\title{
The determinants of the propensity to receive publicly funded home care services for the elderly in Canada: a panel two-stage residual inclusion approach
}

\author{
Gustavo Mery ${ }^{1,2^{*}}$, Walter P. Wodchis ${ }^{1,2}$ and Audrey Laporte ${ }^{1,2}$
}

\begin{abstract}
The role of Home Care $(\mathrm{HC})$ services for the elderly will be increasingly important in meeting populations' future needs for care. HC services include Home Health Care (HHC) and Homemaking/Personal Support (HMPS), distinction rarely seen in the literature. This paper argues that it is important to distinguish between these types of $\mathrm{HC}$, since the factors that drive the likelihood of the receipt of each type of care may differ, and also to investigate the interrelationship between them. We explored the interrelationship between receipt of publicly funded HMPS and $\mathrm{HHC}$, and the determinants of the receipt of each type of services. A Panel Two-Stage Residual Inclusion approach was applied to estimate the likelihood of the receipt of HC services using data for those aged 65 and over from 9 biannual waves of the Canadian National Population Health Survey (1994-95 to 2010-11). We found that there are in fact differences in the determinants of the likelihood of HHC and HMPS receipt. Moreover, receipt of publicly funded HMPS was found to be complementary with receipt of publicly funded HHC services after adjusting for functional and health status. Dependence on help with activities of daily living, health status, household arrangement, and income were found to be determinants of the propensity to receive both publicly funded HHC and HMPS services. This study aims to contribute to the existent literature by taking a step toward explicitly modelling the potential interaction between the determinants of the receipt of different types of $\mathrm{HC}$ services simultaneously, as a system. Our methodological approach, a Panel Two-Stage Residual Inclusion method, seems to effectively address problems that are known to be a source of bias in the literature.
\end{abstract}

Keywords: Home care, Elderly, Long-term care, Public provision, Complementary effect, Determinants

\section{Background}

One anticipated consequence of the aging of societies around the world is an increase in the prevalence of chronic conditions and disability and a higher demand for long-term care, including home care $(\mathrm{HC})$ services. The need for long-term care services is expected to dramatically increase worldwide, at least during the coming four decades $[1,2]$. By 2050, the number of people around the world 80 years of age and older will increase

\footnotetext{
* Correspondence: gustavo.mery@utoronto.ca

${ }^{1}$ Institute of Health Policy, Management and Evaluation, University of

Toronto, Health Sciences Building, 155 College Street, Suite 425, Toronto, ON M5T3M6, Canada

${ }^{2}$ Canadian Centre for Health Economics/Centre canadien en économie de la santé, 155 College Street, Toronto, ON M5T3M6, Canada
}

fourfold, and the global dependency ratio for this age group, relative to the ratio for the population aged 15 to 64, will increase more than threefold [2]. The provision of social care services is likely to grow much faster than the provision of medical treatments by hospitals and doctors [3, 4]. Consequently, the role of $\mathrm{HC}$ services will be increasingly important in meeting populations' future needs for care.

In this study, the distinction between Home Health Care (HHC) services and Homemaking/Personal Support (HMPS) services is made. HHC services include nursing care, physiotherapy, nutritional counselling, and other health care services delivered by professional health care staff. In contrast, HMPS services help people with daily tasks, such as meal preparation, eating, toileting, personal

\section{定}

(c) 2016 Mery et al. Open Access This article is distributed under the terms of the Creative Commons Attribution 4.0 International License (http://creativecommons.org/licenses/by/4.0/), which permits unrestricted use, distribution, and reproduction in any medium, provided you give appropriate credit to the original author(s) and the source, provide a link to the Creative Commons license, and indicate if changes were made. 
hygiene, medication reminders, laundry, light housekeeping, shopping, and transportation [5-7]. These are usually referred to as Activities of Daily Living/InstrumentalADLs (ADL/IADLs). Most HHC services are provided by paid (formal) caregivers (e.g., community nurses), while HMPS services are provided primarily by either paid (e.g., personal support workers) or informal, unpaid caregivers (e.g., spouses, family members, or friends).

Despite the differences between HHC and HMPS services, distinctions are often not made in the literature. The distinction may be an important one however, since there are likely to be differences in the determinants of the demand for these two types of services. For example, an early discharge from hospital may be supported by post-acute nursing care at home, while a senior suffering from dementia will mostly require help with ADL/IADL. Equally important is the different potential for substitution for informal care. While a functional spouse will provide support with personal care, he or she will hardly be able to replace the role of providers of more medically intensive services. The need, access, availability of subsidies, and the potential for substitution among public, private, and informal care within each service type are all expected to differ.

There is also the issue that once an individual has received either HHC or HMPS services that this may influence the likelihood that they receive the other type of service. Most jurisdictions in North America and Europe allocate HC services primarily based on users' need. However, it might be the case, as with other health and social services, that once seniors enter the system, the likelihood of receipt of additional services is higher at lower levels of need. This represents not only an issue of inequitable allocation of scarce resources; with capped budgets and overall service volume constraints [8], receipt of HHC or HMPS services for factors other than need can translate into leaving those who are most deprived without any assistance.

The primary objectives of this study were to explore the determinants of the receipt of publicly funded HHC and HMPS; and by modelling the types of services jointly, to determine whether publicly funded HHC and HMPS services are complements or substitutes in the Canadian context. The analysis also pays particular attention to whether socio-economic factors affect the likelihood of the receipt of publicly funded $\mathrm{HC}$ services.

\section{Background literature}

\section{The determinants of the receipt of HC services}

Age and dependence on help with ADLs/IADLs have been consistently reported as factors that increase the receipt of $\mathrm{HC}$ services of any type and from any source [9-23] and, together with health status, are generally used to indicate users' need for HC services. Household income and living arrangement are also among the determinants of $\mathrm{HC}$ receipt consistently reported in the literature, although their effect may be expected to vary considerably in different contexts. A summary of findings from the literature on the determinants of the receipt of $\mathrm{HC}$ services is presented in Table 1.

It is worth noting that all the studies cited in relation to the effect of income on $\mathrm{HC}$ made no distinction between HHC and HMPS services, with the exception of Meinow et al.'s [17], which only considered HMPS services. Consequently, we cannot infer from the literature whether the effect of income on receipt of publicly funded HHC and HMPS differs.

\section{The relationship between publicly funded HHC and HMPS services}

U.S.-based studies generally do not make the distinction between HHC services and HMPS services, and they usually use the term "home health care" to refer to both health care and social services delivered at home. The main reason for this seems to be that Medicare and Medicaid fund both HHC and HMPS services for eligible users. In contrast, several European studies acknowledge this distinction $[17,21,24]$. This is not surprising given that in many countries in Europe, HHC services are part of the national health care system, while HMPS services fall under municipal governments.

Two recent European studies using 2004 data from the Survey of Health, Ageing and Retirement in Europe (SHARE), which includes data from 18 European countries, supports the importance of making the distinction between HHC and HMPS, since informal care was found to be a substitute for HMPS yet a complement to HHC [22] and to appointments with a doctor and hospital visits [25]. However, the interrelationship between publicly funded HHC and HMPS services was not directly explored.

In Canada, a number of studies have made the distinction between HHC and HMPS services, but only for descriptive purposes [19, 26-28]. Specific analysis of determinants of receipt of these two types of $\mathrm{HC}$ services has not been conducted.

$\mathrm{Up}$ to this point, the literature has treated $\mathrm{HC}$ as one homogenous type of services or has explored HHC and HMPS separately. However, in addition to the evident difference between these types of services, as we noted above, there is potentially a system of interactions between them that has not yet been explored. In order to effectively understand the determinants of the receipt of $\mathrm{HC}$ services, modeling the simultaneous effect of the receipt of different types of services is required. This study represents a step toward trying to explicitly model this interaction in an effort to address this research gap in the literature. 
Table 1 Background literature - the determinants of the receipt of HC services

\begin{tabular}{|c|c|c|c|}
\hline $\begin{array}{l}\text { Determinant of } \\
\text { HC receipt }\end{array}$ & Study reference & Country/region & Findings (or variable used if indicated) \\
\hline Age & \multirow[t]{2}{*}{ [9-23] } & \multirow{2}{*}{$\begin{array}{l}\text { US, UK, The Netherlands, } \\
\text { Sweden, Ontario, Finland, } \\
\text { Europe. }\end{array}$} & \multirow{2}{*}{$\begin{array}{l}\text { Increase the receipt of HC services of any type and from any source. } \\
\text { Together with health status, are generally used to indicate users' need } \\
\text { for } \mathrm{HC} \text { services }\end{array}$} \\
\hline $\begin{array}{l}\text { Dependence on } \\
\text { help with ADLs/ } \\
\text { IADLs }\end{array}$ & & & \\
\hline \multirow[t]{3}{*}{ Health status } & {$[15,16,42]$} & US & $\begin{array}{l}\text { Variables used: Self-rated health measure and a list of chronic conditions, } \\
\text { including heart disease, stroke, diabetes, cancer, arthritis, and incontinence. }\end{array}$ \\
\hline & {$[18]$} & The Netherlands & Variables used: Several chronic physical and mental conditions. \\
\hline & {$[26]$} & Ontario & $\begin{array}{l}\text { Variable used: Individual's level of morbidity, characterized in terms of } 12 \\
\text { clinical groupings. }\end{array}$ \\
\hline \multirow[t]{6}{*}{ Household income } & [43] & The Netherlands & $\begin{array}{l}\text { Higher utilization of publicly funded } \mathrm{HC} \text { among lower income seniors, within } \\
\text { a system that makes copayments proportional to income. }\end{array}$ \\
\hline & {$[20]$} & Finland & $\begin{array}{l}\text { Higher level of utilization of publicly funded HC services among higher } \\
\text { income seniors, without copayments by users. }\end{array}$ \\
\hline & {$[17]$} & Sweden & $\begin{array}{l}\text { Did not find a significant effect of income on allocation of HMPS hours, } \\
\text { within a system that also has no copayments. }\end{array}$ \\
\hline & {$[15]$} & US & $\begin{array}{l}\text { Nonsignificant differences in Medicare HC expenditures according to income, } \\
\text { using merged data from the } 1995 \text { wave of the Asset and Health Dynamics } \\
\text { Among the Oldest-Old (AHEAD) and the } 1998 \text { wave of the Health and Retirement } \\
\text { Study. }\end{array}$ \\
\hline & {$[16]$} & US & $\begin{array}{l}\text { Lower Medicare HC expenditures for higher income seniors using the } 1993 \\
\text { and } 1995 \text { waves of the AHEAD survey. }\end{array}$ \\
\hline & {$[26]$} & Ontario & $\begin{array}{l}\text { Higher receipt of and higher intensity of publicly funded HC services among } \\
\text { adults who lived in low-income neighbourhoods. }\end{array}$ \\
\hline \multirow[t]{5}{*}{ Living arrangement } & {$[9,10,20,44,45]$} & US, Finland, Canada & Higher levels of formal HC receipt among seniors who lived alone. \\
\hline & {$[46]$} & Canada & $\begin{array}{l}\text { Marital status has been found to be negatively associated with receipt of } \\
\text { publicly funded HC. }\end{array}$ \\
\hline & {$[42]$} & US & $\begin{array}{l}\text { Marital status has been found to be negatively associated with any formal } \\
\mathrm{HC} \text { receipt. }\end{array}$ \\
\hline & {$[17]$} & Sweden & $\begin{array}{l}\text { Coresiding seniors were allocated significantly fewer hours of publicly } \\
\text { funded HMPS than those who lived alone, adhering to the explicit allocation } \\
\text { criteria for public services. }\end{array}$ \\
\hline & {$[21]$} & Finland & $\begin{array}{l}\text { Reported higher levels of publicly funded HMPS and HHC receipt among } \\
\text { seniors who lived alone. }\end{array}$ \\
\hline
\end{tabular}

\section{The home care system in Canada}

At the beginning of the 2000s, estimates suggested that approximately $20 \%$ of formal $\mathrm{HC}$ services in Canada were privately financed, with the remaining $80 \%$ financed by the public sector $[26,29]$. The proportion of public $\mathrm{HC}$ funding in Canada devoted to $\mathrm{HHC}$ services rather than to $\mathrm{HM}$ grew from $43.3 \%$ in $1994-1995$ to $48.6 \%$ in $2003-2004$ [30]. Of all the care provided at home, an estimated $80 \%$ is provided by informal caregivers [31, 32].

Under to the Canada Health Act, with the exception of physicians' services, all services provided at the hospital without any cost to the patient are potentially subject to fees in ambulatory settings. Availability of and eligibility for publicly funded services varies across the 10 Canadian provinces and other national subsystems for nonhospital-based services. This situation generates a conflict when services are transferred from hospitals to homes and community settings.
Across provinces, regional organizations provide a single access point where applicants' needs and eligibility criteria are assessed and matched to appropriate services, including home care, supportive living, or long-term care facilities [33]. Until April 2007, all provinces charged fees for HM services, while HHC services were provided with no charge. Consequently, there is an expectation that an income gradient in publicly funded $\mathrm{HC}$ receipt may be observed up to that date, but exclusively for HM services. After that, the governments of Ontario, Manitoba, Quebec, and PEI removed the co-pay requirement and currently do not charge any direct fees for $\mathrm{HC}$ services. The remaining six provinces, namely, British Columbia, Alberta, Saskatchewan, New Brunswick, Nova Scotia, and Newfoundland, have implemented income-testing procedures for the determination of $\mathrm{HC}$ fees. These testing procedures and corresponding differentiated fees may serve as disincentives to demand for services for higher income 
users and also remove barriers for low-income older adults.

\section{Conceptual framework}

We used a household home care decision model previously developed by the authors [34], in which households allocate time and financial resources subject to resources and technology constraints.

The first component of the model that will be addressed in this study is the relationship between publicly funded HMPS and HHC services. Receipt of one is not expected to serve as a substitute for receipt of the other. Indeed, seniors receiving one kind of service are also expected to receive the other more intensively, given the fact that the main determinants of receipt of both HMPS and HHC services are similar and related mostly to age, dependence on help with ADLs/IADLs, and health status. However, when they are adjusted by these variables, they will not necessarily be complementary in their effects. This represents the first testable hypothesis in the model. If receipt of publicly funded HMPS services and receipt of publicly funded HHC services are complements, then receipt of one will be positively associated with receipt of the other, even after adjustments by functional and health status.

The second testable component comes from the model's assumption that households fully exhaust their allocation of publicly funded $\mathrm{HC}$ services. The effect of receipt of informal care on publicly funded HMPS receipt, after adjustment for variables reflecting need, will be driven by the impact of this care on supply rather than on demand. Whether the dependent senior lives with other family members may influence his or her likelihood of receiving publicly funded HMPS services. For example, if help is needed for meal preparation, the possibility of being included in a "meals on wheels" program is higher if a person lives alone than if he or she lives with a functional partner. The probability of receiving help with household chores is also likely to be lower if the dependent senior is coresiding with children. Consequently, the availability of informal care from a coresident family member is expected to negatively affect the likelihood of receiving publicly funded HMPS services. A care receiver's living arrangement will be closely related to the availability of help with ADLs/IADLs. Therefore, household arrangement may be considered a proxy for informal care from coresident caregivers and may be used to test this hypothesis. If informal HMPS services from coresident family members substitute for publicly funded HMPS services, living in a shared household arrangement will be negatively associated with the likelihood of receiving publicly funded HMPS services.

Another testable hypothesis is that allocation of publicly funded $\mathrm{HC}$ services is expected to be determined mostly by variables that reflect need (age, disability, dependence on help with ADLs, and chronic conditions). However, income is a constraint in the theoretical model, and so an effect of income on the likelihood of receiving publicly funded HMPS services is expected, due to scaled out-ofpocket contributions based on income assessments implemented in Canada over the study period.

\section{Methods \\ Data and study population}

Data for this study were derived from the household component of the National Population Health Survey (NPHS) held by Statistics Canada. The NPHS is a nationally representative longitudinal survey that collected data biennially from a panel of approximately 17,000 people for 18 years [35]. All nine waves of the NPHS were used for this study, covering the period from 1994-95 to 2010-11. The sample size ranged between 2302 and 2585 per wave, with a total of 7255 subjects included, and each one observed in 3 waves on average. A total of 22,490 observations were included in the analysis.

The study population was defined as people 65 years of age and older, who were residing in a community dwelling in one of the 10 Canadian provinces for at least one year during the study's time frame. Individuals who turned 65 years of age during the course of the 16 years of observation were included for the waves in which they met the inclusion criteria. Individuals with incomplete follow-up information or who died were included in the waves in which data were available. This was therefore an unbalanced panel data set.

\section{Study variables}

The outcome variables of the study were the probability of receipt of publicly funded HMPS, and the probability of receipt of $\mathrm{HHC}$ services. The NPHS also inquires about the type of services received and allows for more than one positive answer. The variables of the study are presented and described in Table 2. Household arrangement was used as a proxy for informal care.

The inclusion of variables in the model was guided by the elements contained in the conceptual framework and grouping criteria were guided by frequency distribution. Alternative variable types and their different impacts on the model, and also interaction terms and collinearity were explored. For model selection criteria, an Akaike's Information Criterion (AIC) was used.

\section{Statistical analysis}

Simultaneous eligibility for HHC and HMPS services may possibly produce a problem of endogeneity when modelling the effect of one on the other, causing biased results due to the correlation of these predictors with 
Table 2 Study variables

\begin{tabular}{lll}
\hline Outcome variables & Variable type & Description \\
\hline Receipt of publicly funded HHC services & Dichotomous & $\begin{array}{l}\text { If there was a report of the receipt of nursing care and/or } \\
\text { other health care services. }\end{array}$ \\
Receipt of publicly funded HMPS services & $\begin{array}{l}\text { If there was a report of the receipt of personal care, } \\
\text { housework, meal preparation, or delivery, shopping, and/or } \\
\text { respite care. }\end{array}$
\end{tabular}

Explanatory Variables

Household arrangement

Sex*partner

Income

Wave

Health status: diabetes, arthritis, heart disease, stroke, Dichotomous Alzheimer's disease or other dementia, emphysema, cancer, and urinary incontinence.

More than 3 chronic conditions

Hospital

Disability

Dependence

Age

Sex

Minority

Immigrant

Dichotomous
Dichotomous

Dichotomous

Categorical: alone ${ }^{a}$, partner, or 'other adult'

Interaction term

Categorical: low, middlea or high

Ordinal: 1 to 9

Dichotomous

Categorical: high, middle, low, or no-dependence ${ }^{a}$

Continuous

Dichotomous

Dichotomous
Living alone, living with a partner, or living with other adult but not with a partner. The cases when seniors were living with a partner and with other family members were included in the category "partner". These categories were chosen on the basis of the conceptual model and according to frequency distribution.

Categories were taken from the NPHS, which considers the household income adjusted for the number of household members. Grouping criteria were according to the frequency distribution of the survey variable.

The "wave" variable included in each one of the adjusted panel data models was used to observe trends in the propensity to receive $\mathrm{HC}$ of each type over the study time frame and the trend's statistical significance, adjusted by covariates.

Health status was measured using dichotomous variables for several chronic conditions that may have important impacts on functional ability or that generate a need for health care services that may potentially be met at home (one variable per chronic condition).

The presence of and interaction between multiple chronic conditions was considered through the inclusion of a binary variable if the individual indicated more than three chronic conditions.

If respondents had any overnight stays in a hospital in the last 12 months.

If respondents had any long-term disabilities or handicaps.

The NPHS measures need for help with five different ADLs:

a) High-dependence: need for help with preparing meals or with personal care (such as washing, dressing, or eating) and/ or moving around inside the house.

b) Middle-dependence: no need for help with the previous two ADLs, but need for help with shopping for groceries or other necessities, and/or with doing normal, everyday housework.

c) Low-dependence: no need for help with the previously mentioned four ADLs, but need for help with heavy household chores.

d) No-dependence: no need for help with any of the above-mentioned ADLs.

In years.

$0=$ female, $1=$ male.

Self identification as member of an ethnic minority.

Self identification as an immigrant. 
Table 2 Study variables (Continued)

\begin{tabular}{|c|c|c|}
\hline Education & Dichotomous & $\begin{array}{l}0=\text { incomplete secondary education or lower; } 1=\text { completed } \\
\text { secondary education or higher. }\end{array}$ \\
\hline Urban & Dichotomous & $0=$ rural; $1=$ urban. \\
\hline Province & $\begin{array}{l}\text { Categorical: NF, PEl, NS, NB, } \\
\text { QC, ONª, MA, SK, AL, or BC. }\end{array}$ & Province of residence at the point of inclusion in the sample. \\
\hline Social support & $\begin{array}{l}\text { Categorical: low, middle }{ }^{a} \text {, or } \\
\text { high social support. }\end{array}$ & $\begin{array}{l}\text { This variable captured elements of emotional and social } \\
\text { support that are not essential elements of informal } \\
\text { caregiving, but which may affect the likelihood of the receipt } \\
\text { of HMPS services. This categorical variable was derived from a } \\
\text { 16-category index. }\end{array}$ \\
\hline
\end{tabular}

${ }^{a}$ Indicates reference category

${ }^{\mathrm{b}}$ Created according to the definition contained in the Canadian Employment Equity Act [47]

the error term. Given these concerns, an instrumental variable (IV) approach was used.

Given the presence of binary outcome variables in this analysis, usual two-stage least square methods are unsuitable. Instead, a Two-Stage Residual Inclusion method was adopted. This approach has been used in health economics to address endogeneity issues through the use of IVs in nonlinear models [16, 22, 36, 37]. However, in the present analysis of a panel data set, the need to account for the time-invariant component of the error term made the use of these models unsuitable. Panel nonlinear regression models have the problem that they do not support two-stage methods, at least in the usual statistics packages, such as Stata. Using instrumental variable probit (ivprobit) in Stata, the problem of an invariant component of the error term across repeated observations remains unresolved, especially in this case, with nine waves of panel data. In addition, "ivprobit" requires the endogenous variable to be continuous, which was not the case in the current study.

\section{Panel two-stage residual inclusion}

To address this problem, an original approach was used, referred to as the Panel Two-Stage Residual Inclusion model. We first specified a reduced form, first-step equation for each wave of the data set separately. Using logistic regression, we predicted the values of the endogenous variable, HMPS, as a function of its lagged values, and a set of explanatory variables:

$$
\begin{aligned}
\text { hmps }_{i t}= & \boldsymbol{f} \\
& \left(\gamma_{1}+\gamma_{2} \text { hmps }_{i t-2}+\gamma_{3} \text { alzheimer }_{i t}\right. \\
& +\gamma_{4} \text { social_low }_{i t}+\gamma_{4} \text { social_high }_{i t} \\
& \left.+\gamma_{6} z_{i t}+\varepsilon_{i t}\right)
\end{aligned}
$$

\section{for $t=$ waves $\{3,4,5,6,7,8,9\}$ of the NPHS}

where HMPS is receipt of publicly funded HMPS and $z$ represents exogenous predictors (age, sex, income, education, minority, immigrant, urban, partner, other adult, province, emphysema, diabetes, heart disease, stroke, incontinence, arthritis, disability, dependence, over 3 chronic conditions). The IVs used exclusively for HMPS were second lagged values of HMPS receipt, dementia, and social support. From this regression, we obtained the residuals predicted for each wave $\left(\hat{r}_{t}^{\text {hmps }}\right)$.

Next we estimated an equation for likelihood of receipt of $\mathrm{HHC}$, as a function of its second lagged values and other explanatory variables including whether the individual had cancer or had been hospitalized along with the same set of variables contained in $\mathrm{z}$ above:

$$
\begin{aligned}
\text { hhc }_{i t}= & \boldsymbol{f}\left(\gamma_{1}+\gamma_{2} \boldsymbol{h h c}_{i t-2}+\gamma_{3} \text { cancer }_{i t}\right. \\
& \left.+\gamma_{4} \text { hospital }_{i t}+\gamma_{4} z_{i t}+\boldsymbol{\varepsilon}_{i t}\right)
\end{aligned}
$$

for $t=$ waves $\{3,4,5,6,7,8,9\}$ of the NPHS

We generated the predicted residuals from this equation for each wave $\left(\hat{r}_{t}^{h h c}\right)$. In both of the first stage equations we used second lagged values to avoid correlation with the error term in the second-stage equations.

\section{Identification of endogenous predictors and exclusion restrictions}

The following IVs were selected and exclusively used in one of the two first-step equations for the identification of each endogenous predictor separately:

a) For receipt of HHC: second lagged values of $\mathrm{HHC}$ receipt, cancer, and hospital admission.

Receipt of publicly funded HHC services in previous cycles is expected to affect current HHC receipt yet not current HMPS. Regarding hospital admission, post-acute $\mathrm{HC}$ is prescribed after in-hospital stays to allow an early discharge through health services that can be delivered safely at home. Even though post-acute HMPS is also prescribed, these services are only provided concurrently with $\mathrm{HHC}$ after a hospital discharge. Canadian examples of these programs are Aging at Home and Home First in Ontario [38, 39]. Similarly, cancer patients managed at 
home receive professional services, and HMPS is only supplementary to HHC. In fact, in our sample, patients with an acute hospital admission in the past 12 months received $49 \%$ more HHC than HMPS, a difference that reaches $71 \%$ among cancer patients.

b) For receipt of HMPS: second lagged values of HMPS receipt, dementia, and social support.

Similarly, past HMPS receipt is expected to affect current HMPS receipt yet not the current receipt of HHC. In addition, home care services for dementia patients are mostly directed to provide support and respite to family caregivers [40] rather than HHC services. The variable social support, as previously described, captures elements of emotional and social support exclusively related to HMPS.

\section{Second-stage equation}

For the second-stage equations, panel logistic regression ("xtlogit" in Stata) with random-effects was used to specify receipt of HHC as a function of HMPS and other explanatory variables, and the residuals from the first stage HMPS equation described above were included to correct for the potential endogeneity of HMPS. We also specified HMPS as a function of $\mathrm{HHC}$ and other explanatory variables, including the residuals from the first stage HHC equation. Standard errors were estimated by bootstrapping. The second-stage HHC and HMPS equations were estimated as follows:

$$
\begin{aligned}
& \text { hhc }_{i t}=\boldsymbol{f}\left(\beta_{1}+\beta_{2} \text { hmps }_{i t}+\beta_{3} z_{i t}+\beta_{4} \text { cancer }_{i t}\right. \\
& \left.+\beta_{5} \text { hospital }_{i t}+\beta_{6} \text { wave }_{i t}+\hat{\boldsymbol{r}}_{i t}^{\text {hmps }}+\boldsymbol{\varepsilon}_{i t}\right) \\
& \text { hmps }_{i t}=\boldsymbol{f}\left(\beta_{1}+\beta_{2} \text { hhc }_{i t}+\beta_{3} \text { alzheimer }_{i t}\right.
\end{aligned}
$$

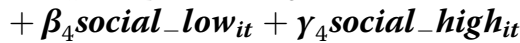

$$
\begin{aligned}
& \left.+\beta_{3} z_{i t}+\beta_{4} \text { wave }_{i t}+\hat{\boldsymbol{r}}_{i t}^{\text {hhc }}+\boldsymbol{\varepsilon}_{i t}\right)
\end{aligned}
$$

The significance of residual terms included in the second-stage equations was taken as a test for endogeneity [41]. To test the strength of the instrumental variables, nonlinearity prevented us from observing the F-test statistics. Instead, we tested the combined effect of the instrumental variables on the endogenous variable in the reduced form equations through chi-square tests. We also checked the increase in standard error, as compared with the noninstrumented model. A Hausman test was used to select random over fixed-effects.

To assess the robustness of the model the results were compared with an equivalent analysis using panel probit and Generalized Estimating Equations $(\mathrm{GEE})^{2}$ specifications. In addition, the results were compared with those obtained from a noninstrumented panel logit approach. In general, for all the analyses performed, results were reported if a $10 \%$ significance level was achieved.

All statistical analyses were performed using STATA 12.0 (StataCorp, 2011). Ethics approval for this research was granted by the Health Sciences Research Ethics Board of the University of Toronto (Protocol Reference \# 27512, April 5, 2012).

\section{Results}

Descriptive statistics are presented in Tables 3 and $4 .{ }^{3}$ The proportion of seniors in the sample who reported receipt of publicly funded $\mathrm{HC}$ services was $10.7 \%$, with $7.9 \%$ receiving HMPS, $4.9 \% \mathrm{HHC}$, and $2.1 \%$ both. A total of $53.4 \%$ lived with a partner; with the proportion of seniors living alone higher among those who received publicly funded HMPS services. An income gradient for $\mathrm{HC}$ receipt was evident in the comparative results.

In the panel logit two-stage residual inclusion analysis, the receipt of HMPS services significantly increased the likelihood of $\mathrm{HHC}$ receipt $(\mathrm{OR}=3.85$, $p<0.001$; Table 5). Evidence of endogeneity of the variable HMPS was observed, with a significant tstatistic on the included residuals $(p=0.062)$, meaning that receipt of $\mathrm{HHC}$ was endogenous to receipt of HMPS services. The strength of the instruments was tested, and the average value of the chi-square test was 29.54 $(p<0.001$; Table 6$)$. In addition, the standard error of the correlation coefficient for the instrumented HMPS predictor was only 1.18 times larger than the noninstrumented variable. The instruments' strength was considered adequate.

There was a positive and significant association between $\mathrm{HHC}$ receipt and the propensity to receive HMPS services $(\mathrm{OR}=13.7, p<0.001)$. However, the included residuals were nonsignificant at the $10 \%$ level $(p=0.595)$. Given the simultaneous effect between receipt of HMPS and HHC services, and the significant evidence of endogeneity in the previous model, the instrumented model was preferred in both cases. Notwithstanding, the coefficients on the other variables in the model were, in general, stable when the residuals were included compared to when they were dropped out, as can be observed in Table 5. Regarding the strength of the instruments, the average value of the chi-square test was $47.13(p<0.001)$ and the standard error of the correlation coefficient for the instrumented HHC predictor was 0.91 times larger than the noninstrumented variable, which was considered adequate.

Household arrangement was a proxy for receipt of informal care in this analysis. In line with the hypothesis, living with other adult family members was associated with a significant decrease in the likelihood of receipt of 
Table 3 Descriptive statistics of the variables included in the adjusted analysis

\begin{tabular}{|c|c|c|c|}
\hline Number of observations & 22,490 & & \\
\hline Number of subjects & 7,255 & & \\
\hline$\overline{\mathrm{HC}}$ & $10.7 \%$ & Social support & \\
\hline $\mathrm{HHC}$ & $4.9 \%$ & Low & $4.7 \%$ \\
\hline HMPS & $7.9 \%$ & Middle & $12.1 \%$ \\
\hline HHC \& HMPS & $2.1 \%$ & High & $83.2 \%$ \\
\hline Age & $74.8 \pm 7.2$ & Need help & $40.4 \%$ \\
\hline Sex (male) & $41.6 \%$ & Moving inside the house & $6.0 \%$ \\
\hline Urban & $84.0 \%$ & Preparing meals & $9.3 \%$ \\
\hline Ethnic minority & $15.4 \%$ & Personal care & $8.9 \%$ \\
\hline Immigrant status & $24.4 \%$ & Shopping & $15.7 \%$ \\
\hline Living arrangement & & Cleaning the house & $17.0 \%$ \\
\hline Living alone & $35.8 \%$ & Heavy household duty & $38.2 \%$ \\
\hline Living with partner & $53.4 \%$ & Dependence & \\
\hline only with partner & $47.1 \%$ & No & $59.6 \%$ \\
\hline with partner \& other adult & $6.3 \%$ & Low & $18.2 \%$ \\
\hline Living with other adult & $10.8 \%$ & Middle & $10.7 \%$ \\
\hline Secondary education completed or higher & $55.7 \%$ & High & $11.5 \%$ \\
\hline & & Health status variables & \\
\hline Income adequacy & & Any chronic condition & $87.7 \%$ \\
\hline Low & $17.5 \%$ & Number of chronic conditions & $2.6 \pm 2.0$ \\
\hline Middle & $37.7 \%$ & 0 & $12.7 \%$ \\
\hline High & $44.9 \%$ & $1-3$ & $59.6 \%$ \\
\hline Province & & $>3$ & $27.7 \%$ \\
\hline NF & $1.6 \%$ & Hospitalization & $11.8 \%$ \\
\hline PEI & $0.4 \%$ & Disability & $29.6 \%$ \\
\hline NS & $3.1 \%$ & Diabetes & $14.2 \%$ \\
\hline NB & $2.6 \%$ & Arthritis & $46.9 \%$ \\
\hline QC & $23.1 \%$ & Heart Disease & $18.0 \%$ \\
\hline ON & $39.7 \%$ & Stroke & $5.0 \%$ \\
\hline MA & $3.8 \%$ & Dementia & $3.6 \%$ \\
\hline SK & $3.2 \%$ & Emphysema & $5.9 \%$ \\
\hline $\mathrm{AL}$ & $8.5 \%$ & Cancer & $5.0 \%$ \\
\hline$B C$ & $14.0 \%$ & Incontinence & $10.8 \%$ \\
\hline
\end{tabular}

publicly funded HMPS services ("other_adult": OR = 0.40; $p<0.003)$. Living with a partner was found to be nonsignificant in general ("partner": $\mathrm{OR}=0.81 ; p=0.417$ ); however, the interaction term between sex (male) and living with partner was found to be significantly negative ("sex(male)*partner": $\mathrm{OR}=0.23 ; p<0.001$ ), a finding that may be interpreted as a substitution effect in relation to informal care provision only by a female partner for a male dependent. As expected on the basis of the conceptual framework, the availability of informal care was nonsignificant in affecting $\mathrm{HHC}$ receipt.
The income variable had a significant effect on the propensity to receive HMPS services, with significantly fewer services for higher-income people $(\mathrm{OR}=0.54, p=0.001)$, as compared with the middle income-adequacy category, and with no observed significant difference between low- and middleincome seniors. Unexpectedly, high-income seniors reported a significantly lower likelihood of $\mathrm{HHC}$ receipt $(\mathrm{OR}=0.64, p=0.007)$, and low-income seniors reported a significantly higher likelihood of $\mathrm{HHC}$ receipt $(\mathrm{OR}=1.39, p=0.080)$. 
Table 4 Comparative descriptive statistics by categories of HC receipt

\begin{tabular}{|c|c|c|c|c|c|c|c|}
\hline \multirow[b]{2}{*}{ Age } & & \multirow{2}{*}{$\begin{array}{l}\text { HMPS } \\
80.2 \pm 0.17\end{array}$} & \multicolumn{2}{|l|}{ No HMPS } & \multirow{2}{*}{$\begin{array}{l}\mathrm{HHC} \\
78.1 \pm 0.23\end{array}$} & \multicolumn{2}{|l|}{$\mathrm{No} \mathrm{HHC}$} \\
\hline & & & $73.9 \pm 0.05$ & **** & & $74.2 \pm 0.05$ & $* * *$ \\
\hline Sex (male) & & $32.9 \%$ & $42.9 \%$ & $* * *$ & $40.6 \%$ & $42.2 \%$ & \\
\hline Minority & & $14.3 \%$ & $15.6 \%$ & & $12.2 \%$ & $15.6 \%$ & $* *$ \\
\hline Immigrant & & $21.0 \%$ & $24.8 \%$ & $* *$ & $22.6 \%$ & $24.6 \%$ & \\
\hline Alone & & $54.3 \%$ & $31.7 \%$ & $* * *$ & $43.9 \%$ & $32.9 \%$ & $* * *$ \\
\hline Partner & & $36.0 \%$ & $57.1 \%$ & $* * *$ & $43.5 \%$ & $56.0 \%$ & $* * *$ \\
\hline Other_adult ${ }^{\mathrm{a}}$ & & $9.7 \%$ & $11.2 \%$ & & $12.7 \%$ & $11.0 \%$ & \\
\hline Education $^{\text {b }}$ & & $50.0 \%$ & $56.2 \%$ & $* * *$ & $47.6 \%$ & $56.1 \%$ & $* * *$ \\
\hline \multirow[t]{3}{*}{ Income $e^{c}$} & Low & $30.0 \%$ & $15.3 \%$ & $* * *$ & $23.0 \%$ & $16.1 \%$ & $* * *$ \\
\hline & Middle & $43.2 \%$ & $37.3 \%$ & $* * *$ & $47.3 \%$ & $37.3 \%$ & $* * *$ \\
\hline & High & $26.8 \%$ & $47.4 \%$ & $* * *$ & $29.8 \%$ & $46.6 \%$ & $* * *$ \\
\hline Urban & & $81.6 \%$ & $83.9 \%$ & $* *$ & $82.9 \%$ & $83.7 \%$ & \\
\hline \multirow[t]{4}{*}{ Dependency } & No & $8.4 \%$ & $64.0 \%$ & $* * *$ & $18.5 \%$ & $61.7 \%$ & $* * *$ \\
\hline & Low & $14.9 \%$ & $18.5 \%$ & $* *$ & $14.3 \%$ & $18.4 \%$ & $* *$ \\
\hline & Middle & $25.6 \%$ & $9.4 \%$ & $* * *$ & $19.7 \%$ & $10.3 \%$ & $* * *$ \\
\hline & High & $51.1 \%$ & $8.1 \%$ & $* * *$ & $47.5 \%$ & $9.6 \%$ & $* * *$ \\
\hline \multicolumn{2}{|c|}{ Over 3 chronic conditions } & $50.1 \%$ & $25.8 \%$ & $* * *$ & $51.4 \%$ & $26.6 \%$ & *** \\
\hline \multicolumn{2}{|l|}{ Disability } & $63.5 \%$ & $25.1 \%$ & $* * *$ & $59.1 \%$ & $26.6 \%$ & *** \\
\hline \multicolumn{2}{|l|}{ Diabetes } & $22.9 \%$ & $13.2 \%$ & $* * *$ & $24.0 \%$ & $13.5 \%$ & *** \\
\hline \multicolumn{2}{|l|}{ Heart disease } & $31.7 \%$ & $16.2 \%$ & $* * *$ & $35.3 \%$ & $16.5 \%$ & $* * *$ \\
\hline \multicolumn{2}{|l|}{ Stroke } & $13.6 \%$ & $3.6 \%$ & $* * *$ & $13.4 \%$ & $3.9 \%$ & $* * *$ \\
\hline \multicolumn{2}{|l|}{ Arthritis } & $64.0 \%$ & $45.0 \%$ & $* * *$ & $61.2 \%$ & $45.7 \%$ & *** \\
\hline \multicolumn{2}{|l|}{ Dementia } & $7.0 \%$ & $1.4 \%$ & $* * *$ & $6.4 \%$ & $1.6 \%$ & *** \\
\hline \multicolumn{2}{|l|}{ Emphysema } & $12.4 \%$ & $5.3 \%$ & $* * *$ & $11.7 \%$ & $5.5 \%$ & *** \\
\hline \multicolumn{2}{|l|}{ Cancer } & $8.0 \%$ & $4.7 \%$ & $* * *$ & $13.7 \%$ & $4.5 \%$ & *** \\
\hline \multicolumn{2}{|l|}{ Incontinence } & $19.4 \%$ & $8.3 \%$ & $* * *$ & $20.8 \%$ & $8.5 \%$ & *** \\
\hline \multicolumn{2}{|l|}{ Hospitalization } & $39.3 \%$ & $13.8 \%$ & $* * *$ & $58.4 \%$ & $13.6 \%$ & *** \\
\hline \multirow[t]{3}{*}{ Social support } & Low & $10.4 \%$ & $5.5 \%$ & $* * *$ & $6.8 \%$ & $5.8 \%$ & \\
\hline & Middle & $17.1 \%$ & $12.6 \%$ & $* *$ & $15.1 \%$ & $12.8 \%$ & \\
\hline & High & $72.5 \%$ & $81.9 \%$ & $* * *$ & $78.2 \%$ & $81.4 \%$ & \\
\hline
\end{tabular}

* Significant at the $10 \%$ level. ** Significant at the $5 \%$ level. *** Significant at the $1 \%$ level

a Living without a partner but with other adult(s)

${ }^{\mathrm{b}}$ Secondary education completed or higher

c Household income adequacy (adjusted by household members) 
Table 5 HMPS and HHC receipt - second stage panel Logit analysis with and without IV

\begin{tabular}{|c|c|c|c|c|c|c|c|c|c|}
\hline \multicolumn{2}{|c|}{ Dependent Variable $\rightarrow$} & \multicolumn{4}{|l|}{ HMPS } & \multicolumn{4}{|l|}{$\mathrm{HHC}$} \\
\hline & & \multicolumn{2}{|l|}{ With IV } & \multicolumn{2}{|l|}{ Without IV } & \multicolumn{2}{|l|}{ With IV } & \multicolumn{2}{|l|}{ Without IV } \\
\hline & & OR (SE) & $P$ & OR (SE) & $p$ & $\mathrm{OR}(\mathrm{SE})$ & $p$ & $\mathrm{OR}(\mathrm{SE})$ & $p$ \\
\hline \multicolumn{2}{|l|}{ HMPS } & - & - & - & - & $3.848(.982)$ & .000 & $4.850(.566)$ & .000 \\
\hline \multicolumn{2}{|l|}{$\mathrm{HHC}$} & $13.71(5.240)$ & .000 & $12.57(2.509)$ & .000 & - & - & - & - \\
\hline \multicolumn{2}{|l|}{ Residuals HMPS } & - & - & - & - & $1.130(.074)$ & .062 & - & - \\
\hline \multicolumn{2}{|l|}{ Residuals HHC } & $.944(.103)$ & .595 & - & - & - & - & - & - \\
\hline \multicolumn{2}{|l|}{ Wave } & $.909(.030)$ & .004 & $.912(.030)$ & .005 & $.951(.038)$ & .212 & $1.044(.021)$ & .033 \\
\hline \multirow[t]{2}{*}{ Income ${ }^{a}$} & low & $1.230(.222)$ & .252 & $1.122(.175)$ & .459 & $1.390(.262)$ & .080 & $.969(.117)$ & .795 \\
\hline & high & $.541(.099)$ & .001 & $.551(.094)$ & .000 & $.635(.107)$ & .007 & $.678(.084)$ & .002 \\
\hline \multicolumn{2}{|l|}{ Education $^{\text {b }}$} & $1.279(.210)$ & .133 & $1.209(.187)$ & .222 & $1.001(.163)$ & .997 & $.968(.103)$ & .763 \\
\hline \multicolumn{2}{|l|}{ Age } & $1.107(.017)$ & .000 & $1.113(.012)$ & .000 & $1.015(.016)$ & .328 & $1.012(.007)$ & .097 \\
\hline \multicolumn{2}{|l|}{ Sex (male) } & $1.872(.428)$ & .006 & $2.050(.417)$ & .000 & $1.550(.314)$ & .030 & $1.234(.184)$ & .158 \\
\hline \multicolumn{2}{|l|}{ Partner } & $.805(.215)$ & .417 & $.642(.138)$ & .039 & $.854(.227)$ & .553 & $.831(.133)$ & .246 \\
\hline \multicolumn{2}{|l|}{ Other_adult } & $.399(.122)$ & .003 & $.340(.112)$ & .001 & $1.309(.357)$ & .323 & $1.285(.225)$ & .153 \\
\hline \multicolumn{2}{|l|}{ Sex*partner } & $.232(.085)$ & .000 & $.257(.083)$ & .000 & $.820(.306)$ & .591 & $1.147(.250)$ & .529 \\
\hline \multicolumn{2}{|l|}{ Minority } & $.718(.208)$ & .254 & $.753(.197)$ & .278 & $.720(.188)$ & .208 & $.932(.160)$ & .681 \\
\hline \multicolumn{2}{|l|}{ Immigrant } & $.545(.121)$ & .006 & $.514(.115)$ & .003 & $.929(.193)$ & .721 & $.844(.121)$ & .237 \\
\hline \multicolumn{2}{|l|}{ Urban } & .765 (.139) & .141 & .728 (.133) & .082 & $.846(.201)$ & .482 & $.911(.110)$ & .436 \\
\hline \multirow[t]{9}{*}{ Province $^{c}$} & $\mathrm{NF}$ & $.212(.106)$ & .002 & $.232(.099)$ & .001 & $.201(.114)$ & .005 & $.311(.092)$ & .000 \\
\hline & PEI & $.704(.234)$ & .291 & $.716(.226)$ & .290 & $.277(.157)$ & .024 & .405 (.098) & .000 \\
\hline & NS & $.856(.281)$ & .636 & $.825(.251)$ & .527 & $.273(.092)$ & .000 & $.284(.070)$ & .000 \\
\hline & NB & $.986(.275)$ & .961 & $1.072(.317)$ & .813 & $.299(.116)$ & .002 & $.384(.089)$ & .000 \\
\hline & QC & $.428(.112)$ & .001 & $.462(.115)$ & .002 & $.970(.240)$ & .903 & $1.123(.172)$ & .449 \\
\hline & MA & $.676(.203)$ & .191 & $.726(.219)$ & .288 & $.464(.186)$ & .055 & $.543(.112)$ & .003 \\
\hline & SK & $.748(.225)$ & .335 & $.676(.197)$ & .180 & $.595(.209)$ & .140 & $.697(.134)$ & .060 \\
\hline & $A L$ & $.546(.175)$ & .059 & $.514(.163)$ & .036 & $.699(.197)$ & .205 & $.637(.133)$ & .031 \\
\hline & $\mathrm{BC}$ & $.979(.285)$ & .943 & $1.024(.273)$ & .928 & $.282(.109)$ & .001 & $.382(.079)$ & .000 \\
\hline \multirow[t]{3}{*}{ Dependence $^{d}$} & Low & $3.870(.640)$ & .000 & $4.010(.726)$ & .000 & $2.061(.425)$ & .000 & $1.894(.276)$ & .000 \\
\hline & Middle & $13.39(2.817)$ & .000 & $13.36(2.671)$ & .000 & $3.529(.791)$ & .000 & $3.193(.491)$ & .000 \\
\hline & High & $36.39(9.265)$ & .000 & 38.28 (8.337) & .000 & $4.410(1.126)$ & .000 & $4.286(.668)$ & .000 \\
\hline Disability & & $1.545(.234)$ & .004 & $1.631(.222)$ & .000 & $1.186(.190)$ & .287 & $1.291(.136)$ & .015 \\
\hline Over 3 chronic & tions & $.910(.157)$ & .584 & $.878(.136)$ & .403 & $1.233(.232)$ & .266 & $1.253(.150)$ & .059 \\
\hline Diabetes & & $1.351(.329)$ & .218 & $1.447(.268)$ & .046 & $1.198(.229)$ & .345 & $1.124(.145)$ & .367 \\
\hline Heart disease & & $1.183(.201)$ & .323 & $1.152(.178)$ & .359 & .987 (.201) & .949 & $1.112(.124)$ & .340 \\
\hline Stroke & & $1.292(.300)$ & .271 & $1.308(.342)$ & .304 & $1.499(.356)$ & .088 & $1.242(.202)$ & .182 \\
\hline Arthritis & & $1.172(.196)$ & .344 & $1.253(.182)$ & .121 & $1.093(.188)$ & .606 & $1.044(.110)$ & .685 \\
\hline Emphysema & & $1.191(.285)$ & .465 & $1.221(.285)$ & .393 & $.701(.176)$ & .158 & $.849(.143)$ & .330 \\
\hline Incontinence & & $.908(.186)$ & .637 & $.992(.178)$ & .966 & $1.546(.306)$ & .028 & $1.225(.162)$ & .124 \\
\hline Dementia & & $.960(.785)$ & .960 & $.931(.592)$ & .911 & - & - & - & - \\
\hline Cancer & & - & - & - & - & $2.259(.625)$ & .003 & $2.241(.343)$ & .000 \\
\hline
\end{tabular}


Table 5 HMPS and HHC receipt - second stage panel Logit analysis with and without IV (Continued)

\begin{tabular}{|c|c|c|c|c|c|c|c|c|c|}
\hline Hospitalization & & - & - & - & - & $7.377(1.368)$ & .000 & $5.463(.537)$ & .000 \\
\hline \multirow[t]{2}{*}{ Social support } & Low & $.890(.227)$ & 649 & .803 (.194) & .364 & - & - & - & - \\
\hline & High & $.837(.144)$ & .302 & .779 (.124) & .116 & - & - & - & - \\
\hline
\end{tabular}

${ }^{a}$ Reference category: middle-income adequacy

b Secondary education completed or higher

c Reference category: Ontario

d Reference category: No dependency

Age, disability, and dependency were strong predictors of publicly funded HMPS receipt, while stroke, incontinence, cancer, dependency and hospitalization were associated with a higher likelihood of HHC receipt. The analysis showed an increased likelihood of HMPS and HHC receipt by male seniors. Immigrant status was found to be associated with a significantly lower likelihood of HMPS receipt, in spite of the fact that the average time since immigration in our sample was 43.9 years. In contrast, ethnic minority was not a significant predictor in any of the analyses.

Among other demographic variables, urban seniors did not report a significantly different likelihood of the receipt of $\mathrm{HC}$ services. All provinces showed a lower likelihood of $\mathrm{HC}$ receipt as compared to Ontario. However, the sample sizes were limited for the small provinces. Among the four provinces that had higher representation in the sample, residents of Quebec and Alberta had a significantly lower likelihood of HMPS receipt in the adjusted analysis, and residents of British Columbia had a significantly lower likelihood of HHC receipt, as compared to Ontario residents.

The proportion of seniors reporting receipt of public HMPS services decreased significantly over the study's time frame in the adjusted analysis. Receipt of HHC, in contrast, did not show a significant variation.

Even though the trends in the association between predictors and $\mathrm{HC}$ receipt did not change after the inclusion of residuals, there were some changes in the significance of variables, as shown in the second and fourth columns of Table 5. Results from the first stage logit equations are included as Appendices.

Table 6 HMPS and HHC receipt - Chi-square results - First Stage Logit Analysis

\begin{tabular}{lcc}
\hline Wave & HMPS IV & HHC IV \\
\hline 3 & $41.8^{*}$ & $50.5^{*}$ \\
4 & $48.9^{*}$ & $46.6^{*}$ \\
5 & $31.2^{*}$ & $40.0^{*}$ \\
6 & $20.5^{*}$ & $46.0^{*}$ \\
7 & $30.8^{*}$ & $62.7^{*}$ \\
8 & $12.3^{*}$ & $31.0^{*}$ \\
9 & $21.2^{*}$ & $53.2^{*}$ \\
Average & 29.5 & 47.1 \\
\hline${ }^{*} P$-value $<0.001$ & &
\end{tabular}

${ }^{*} P$-value $<0.001$
The results from the preferred model were entirely comparable in terms of the magnitude and direction of effects with those obtained using a panel probit model and weighted GEE analysis in the second-stage equation, although significance levels showed some differences. These results are available upon request.

\section{Discussion}

The $\mathrm{HC}$ literature, up to this point, most frequently treats HHC and HMPS as one homogeneous type of service. Findings in our study support the existence of important differences among them. This research provides robust empirical evidence to confirm part of the hypotheses in our conceptual framework, which translates into a number of important policy implications. In addition, this study is the first attempt to explore and model the potential system of interactions between $\mathrm{HC}$ services of different types.

We found that receipt of publicly funded HHC was complementary to the receipt of publicly funded HMPS services. This finding supports the assumption that, once a senior accesses the $\mathrm{HC}$ system, the probability of being deemed eligible or being offered additional services is higher. The receipt of HMPS was also a strong predictor of $\mathrm{HHC}$ receipt, although weaker than the effect of $\mathrm{HHC}$ as a predictor of HMPS receipt. This finding partially departed from the expectation that receipt of HMPS would be a weak predictor of $\mathrm{HHC}$ receipt. A certain level of qualification is required for assessment of the need for health services, and this type of care is specialized, as compared with HMPS services.

In terms of patient care, the consequence of this complementary effect is an increased gap between care recipients and non-recipients, who are at equivalent levels of functional and health status. This element raises concerns about equitable access to HC services in Canada, especially given that provincial $\mathrm{HC}$ programs are characterized by capped budgets and overall service volume constraints [8]. This finding also raises concerns worth exploring in other systems. In Europe and among US Medicare beneficiaries, this complementary effect may be increasing inequitable access to services, an element not yet studied in these jurisdictions.

Consistent with the theoretical model, we found that the availability of informal care was a negative and significant determinant of the receipt of publicly funded 
HMPS services, when such care was included in the analysis through the use of household arrangement variables. However, living with a partner only significantly reduced the likelihood of receipt of HMPS when the caregiver partner was a female. Living with other adult family members significantly reduced the likelihood of receipt of HMPS. These findings confirm the reliance on family caregiving when allocating publicly funded $\mathrm{HC}$ services, even if eligibility criteria are not explicit in this regard; gender differences are also confirmed. Living arrangement variables were not significant predictors of $\mathrm{HHC}$ receipt, which represent additional evidence to the importance of analyzing different types of $\mathrm{HC}$ services separately. These observations were concurrent with the interactions in the conceptual framework. Observed differences in the determinants of the receipt of HHC and HMPS may translate into unattended needs in systems where eligibility to $\mathrm{HC}$ services is bundled for health and social care, such as the US Medicare system -a hypothesis worth exploring further.

Income was an important determinant of HMPS receipt, with fewer services for high-income seniors, as compared with those in the middle- and low-income categories. These findings were expected because all Canadian provinces charged copayments for HMPS services until 2007, payments that were graduated by income [33]. In addition, the probability of the substitution by privately paid HMPS was also hypothesized to be higher for higher-income seniors. Unexpectedly, we also observed differences according to income in the receipt of HHC services even after we included a large set of controls for health status, with wealthier individuals less likely to receive services. This is somewhat surprising since these services are provided free of charge in every province, regardless of the ability to pay.

The study has several limitations, mostly related to the data source. First, the NPHS asks if subjects received services at home or not, but does not inquire about the intensity of services received, i.e., total amount of hours of care received. Second, receipt of informal care from a coresident family member was only inferred from its availability in terms of living arrangement, since specific information on the actual receipt of informal care was not available at this point. In addition, the NPHS has a reduced number of questions specific to $\mathrm{HC}$ receipt, which limited the scope of questions to be addressed with this data set.

Among the contributions, this study uses 18 years of longitudinal data, which represent an extraordinary opportunity to explore the determinants and interactions in the receipt of $\mathrm{HC}$ services. The results suggest that there are important differences between the drivers of HHC and HMPS service receipt. As regards, the second aim-to explore the potential interactions between the likelihood of receipt of the two types of services, this study represents a first attempt to model the determinants of types of publicly funded $\mathrm{HC}$ receipt as a system. We argued that failure to address the potential for interactive effects in the existing literature may have biased findings to date. The challenge in this study was that the set of potential instruments in the data were few and necessitated use of lagged variables. We explored various specifications to test the robustness of our results and tested the instruments for strength and validity.

Our results remained consistent across the instrumented and noninstrumented approaches, confirming our main research hypotheses. Therefore, the policy implications discussed deserve careful consideration from health care providers and policy makers, to ensure equitable and fair access to health and social support in the home and community settings for the frail elders. Nevertheless, future research should further explore the questions posed within the framework presented in this paper using data that offer a wider set of potentially strong instruments.

The original methodological approach proposed in this study, a Panel Two-Stage Residual Inclusion approach, seems to have yielded sensible results and to have effectively addressed problems that are known to be a source of bias in the literature.

\section{Conclusions}

A conclusion of this study is that the distinction between receipt of HHC and HMPS services matters, given the fact that we found differences in the determinants of the likelihood of HHC and HMPS receipt.

We found a complementary interrelationship between receipt of publicly funded HMPS and HHC services, after adjusting for functional and health status. The consequence of this complementary effect may be an increased gap between care recipients and non-recipients, who are at equivalent levels of functional and health status.

Dependence on help with activities of daily living, health status, household arrangement, and income were significant determinants of the propensity to receive both publicly funded HHC and HMPS services.

Our results suggest that the determinants of receipt of $\mathrm{HC}$ services of different types are more complex than has been acknowledge so far, and that this complexity should be taken into greater consideration in the empirical literature.

\section{Endnotes}

${ }^{1}$ The use of second lagged values in the first-stage equations requires missing waves 1 and 2 in the instrumented model.

${ }^{2}$ The survey weights used for the sampling strategy were included in the GEE model.

${ }^{3}$ Descriptive results are presented using the total number of observations as the denominator (as opposed to total number of individuals), and after adjusting by survey weights. 


\section{Appendices}

Table 7 First stage Logit equations $-\mathrm{HHC}$ receipt (waves 3 to 6)

\begin{tabular}{|c|c|c|c|c|c|c|c|c|c|}
\hline \multirow{3}{*}{\multicolumn{2}{|c|}{ Dependent Variable $\rightarrow$}} & \multicolumn{4}{|l|}{$\mathrm{HHC}$} & \multicolumn{4}{|l|}{$\mathrm{HHC}$} \\
\hline & & \multicolumn{2}{|l|}{ Wave 3} & \multicolumn{2}{|l|}{ Wave 4} & \multicolumn{2}{|l|}{ Wave 5} & \multicolumn{2}{|l|}{ Wave 6} \\
\hline & & OR (SE) & $P$ & OR (SE) & $p$ & OR (SE) & $p$ & OR (SE) & $P$ \\
\hline \multicolumn{2}{|l|}{$H H C C_{t-2}$} & $1.945(.987)$ & .189 & $3.309(1.575)$ & .012 & $2.289(1.068)$ & .076 & $6.873(3.131)$ & .000 \\
\hline \multicolumn{2}{|l|}{ Cancer } & $.841(.361)$ & .687 & $.774(.363)$ & .599 & $2.434(1.151)$ & .069 & $2.200(.966)$ & .072 \\
\hline \multicolumn{2}{|l|}{ Hospitalization } & $5.328(1.267)$ & .000 & $5.606(1.457)$ & .000 & $5.630(1.701)$ & .000 & $5.771(1.755)$ & .000 \\
\hline \multirow[t]{2}{*}{ Income ${ }^{a}$} & Low & $1.248(.332)$ & .404 & $.606(.188)$ & .107 & $2.220(.789)$ & .025 & $1.689(.627)$ & .158 \\
\hline & High & $.481(.173)$ & .042 & $.714(.227)$ & .289 & $.743(.277)$ & .426 & $.600(.229)$ & .180 \\
\hline \multicolumn{2}{|l|}{ Education $^{\mathrm{b}}$} & $.939(.224)$ & .792 & $.726(.193)$ & .228 & $1.067(.321)$ & .829 & $1.054(.317)$ & .861 \\
\hline \multicolumn{2}{|l|}{ Age } & $1.014(.020)$ & .462 & $1.046(.022)$ & .030 & $1.067(.025)$ & .005 & $1.038(.025)$ & .120 \\
\hline \multicolumn{2}{|l|}{ Sex (male) } & $.875(.313)$ & .710 & $2.706(.914)$ & .003 & $1.576(.629)$ & .255 & $1.254(.531)$ & .593 \\
\hline \multicolumn{2}{|l|}{ Partner } & $.754(.280)$ & .448 & $.746(.318)$ & .492 & $1.239(.607)$ & .661 & $1.663(.814)$ & .299 \\
\hline \multicolumn{2}{|l|}{ Other_adult } & $.366(.205)$ & .073 & $.930(.336)$ & .646 & $3.296(1.648)$ & .017 & $1.589(.793)$ & .354 \\
\hline \multicolumn{2}{|l|}{ Sex*partner } & $1.280(.685)$ & .645 & $.294(.172)$ & .036 & $.943(.605)$ & .928 & $.688(.448)$ & .565 \\
\hline \multicolumn{2}{|l|}{ Minority } & $1.013(.422)$ & .974 & .981 (.469) & .968 & $.401(.230)$ & .111 & $.881(.460)$ & .808 \\
\hline \multicolumn{2}{|l|}{ Immigrant } & $.754(.252)$ & .400 & $.380(.151)$ & .015 & $.755(.337)$ & .529 & $1.355(.518)$ & .426 \\
\hline \multicolumn{2}{|l|}{ Urban } & $.784(.239)$ & .424 & $1.011(.344)$ & .974 & 1.019 (.378) & .960 & $.732(.296)$ & .440 \\
\hline \multirow[t]{9}{*}{ Province $^{c}$} & NF & $.462(.281)$ & .205 & $.068(.078)$ & .019 & $.299(.283)$ & .202 & $.154(.169)$ & .088 \\
\hline & PEI & $.146(.115)$ & .015 & $.382(.201)$ & .067 & $.321(.233)$ & .117 & $.922(.543)$ & .890 \\
\hline & NS & $.586(.270)$ & .246 & $.337(.188)$ & .052 & $.111(.117)$ & .038 & $.101(.111)$ & .036 \\
\hline & NB & $.187(.112)$ & .005 & $.786(.380)$ & .618 & $.574(.415)$ & .443 & $.182(.161)$ & .053 \\
\hline & QC & $1.550(.524)$ & .195 & $.504(.194)$ & .075 & $1.604(.660)$ & .250 & $1.430(.604)$ & .398 \\
\hline & MA & $.448(.196)$ & .066 & .369 (.198) & .064 & $.469(.290)$ & .221 & $.530(.366)$ & .358 \\
\hline & SK & $.937(.386)$ & .874 & $.356(.179)$ & .040 & $1.760(.816)$ & .223 & $.437(.277)$ & .191 \\
\hline & $\mathrm{AL}$ & $.337(.195)$ & .060 & $.320(.183)$ & .046 & $1.428(.787)$ & .518 & $.678(.349)$ & .450 \\
\hline & $B C$ & $.438(.208)$ & .082 & $.285(.156)$ & .022 & $.493(.303)$ & .249 & $.420(.257)$ & .156 \\
\hline \multirow[t]{3}{*}{ Dependence $^{d}$} & Low & $3.857(1.525)$ & .001 & $1.473(.587)$ & .331 & $2.413(1.145)$ & .063 & $.980(.526)$ & .970 \\
\hline & Middle & $7.068(2.906)$ & .000 & $3.474(1.373)$ & .002 & $3.882(1.915)$ & .006 & $4.611(2.167)$ & .001 \\
\hline & High & $15.02(6.109)$ & .000 & $4.024(1.616)$ & .001 & $4.727(2.284)$ & .001 & $4.019(1.960)$ & .004 \\
\hline \multicolumn{2}{|l|}{ Disability } & $.935(.246)$ & .800 & $1.820(.513)$ & .034 & $1.406(.438)$ & .273 & $1.352(.431)$ & .344 \\
\hline \multicolumn{2}{|c|}{ Over 3 chronic conditions } & $1.303(.370)$ & .351 & $1.792(.582)$ & .072 & $.910(.338)$ & .800 & $1.531(.557)$ & .242 \\
\hline \multicolumn{2}{|l|}{ Diabetes } & $1.588(.468)$ & .116 & $1.064(.344)$ & .848 & $1.648(.562)$ & .143 & $1.013(.357)$ & .970 \\
\hline \multicolumn{2}{|l|}{ Heart disease } & $.918(.245)$ & .750 & $.824(.247)$ & .518 & $.778(.257)$ & .448 & $1.129(.385)$ & .721 \\
\hline Stroke & & $1.127(.418)$ & .748 & $1.572(.607)$ & .242 & $1.122(.521)$ & .805 & $1.731(.741)$ & .200 \\
\hline Arthritis & & $1.361(.346)$ & .225 & $.774(.210)$ & .346 & $.967(.303)$ & .914 & $.989(.316)$ & .973 \\
\hline Emphysema & & 1.811 (.327) & .603 & $1.369(.555)$ & .438 & $.294(.169)$ & .033 & $.399(.233)$ & .115 \\
\hline Incontinence & & $2.868(.847)$ & .000 & .715 (.296) & .418 & $2.351(.834)$ & .016 & $.479(.201)$ & .080 \\
\hline
\end{tabular}

a Reference category: middle-income adequacy

${ }^{b}$ Secondary education completed or higher

c Reference category: Ontario

${ }^{\mathrm{d}}$ Reference category: No dependency 
Table 8 First stage Logit equations $-\mathrm{HHC}$ receipt (waves 7 to 9)

\begin{tabular}{|c|c|c|c|c|c|c|c|}
\hline \multicolumn{2}{|c|}{ Dependent Variable $\rightarrow$} & \multicolumn{6}{|l|}{$\mathrm{HHC}$} \\
\hline & & \multicolumn{2}{|l|}{ Wave 7} & \multicolumn{2}{|l|}{ Wave 8} & \multicolumn{2}{|l|}{ Wave 9} \\
\hline & & OR (SE) & $P$ & OR (SE) & $p$ & OR (SE) & $p$ \\
\hline \multicolumn{2}{|l|}{$H H C C_{t-2}$} & $1.063(.765)$ & .932 & $2.416(1.441)$ & .139 & $5.413(3.107)$ & .003 \\
\hline \multicolumn{2}{|l|}{ Cancer } & $1.307(.661)$ & .597 & $4.535(2.342)$ & .003 & $5.963(2.672)$ & .000 \\
\hline \multicolumn{2}{|l|}{ Hospitalization } & $10.74(3.273)$ & .000 & $5.469(1.983)$ & .000 & 8.178 (2.883) & .000 \\
\hline \multirow[t]{2}{*}{ Income ${ }^{a}$} & Low & $.848(.359)$ & .698 & $1.032(.565)$ & .953 & $1.184(.607)$ & .742 \\
\hline & High & $.626(.214)$ & .172 & $.875(.355)$ & .742 & $.380(.155)$ & .018 \\
\hline \multicolumn{2}{|l|}{ Education $^{\mathrm{b}}$} & $1.244(.381)$ & .476 & $1.395(.507)$ & .360 & $1.614(.584)$ & .185 \\
\hline \multicolumn{2}{|l|}{ Age } & $1.005(.025)$ & .858 & $.987(.026)$ & .627 & $.978(.027)$ & .413 \\
\hline \multicolumn{2}{|l|}{ Sex (male) } & $.976(.477)$ & .960 & $1.194(.655)$ & .746 & $.875(.504)$ & .817 \\
\hline \multicolumn{2}{|l|}{ Partner } & .735 (.355) & .523 & $.336(.190)$ & .054 & $.670(.368)$ & .465 \\
\hline \multicolumn{2}{|l|}{ Other_adult } & $.611(.345)$ & .383 & $.298(.212)$ & .088 & $1.507(.973)$ & .525 \\
\hline \multicolumn{2}{|l|}{ Sex*partner } & $1.643(1.094)$ & .456 & $1.095(.873)$ & .909 & $2.519(2.008)$ & .247 \\
\hline \multicolumn{2}{|l|}{ Minority } & $1.020(.480)$ & .966 & $.904(.445)$ & .837 & $.278(.186)$ & .055 \\
\hline \multicolumn{2}{|l|}{ Immigrant } & $.733(.325)$ & .483 & $2.135(.909)$ & .075 & $1.272(.572)$ & .593 \\
\hline \multicolumn{2}{|l|}{ Urban } & $.609(.243)$ & .213 & $.692(.338)$ & .451 & $1.150(.607)$ & .791 \\
\hline \multirow[t]{9}{*}{ Province ${ }^{c}$} & $\mathrm{NF}$ & $.233(.251)$ & .177 & 1 (omitted) & & $.732(.608)$ & .707 \\
\hline & PEI & $.296(.218)$ & .099 & 1 (omitted) & & $.638(.576)$ & .619 \\
\hline & NS & $.285(.188)$ & .057 & $.316(.257)$ & .156 & $.292(.324)$ & .267 \\
\hline & NB & $.444(.278)$ & .194 & $.696(.448)$ & .573 & 1.595 (1.052) & .479 \\
\hline & QC & $1.961(.839)$ & .115 & $.444(.248)$ & .146 & $1.415(.742)$ & .508 \\
\hline & MA & $.825(.502)$ & .752 & $.899(.536)$ & .858 & $1.278(.796)$ & .694 \\
\hline & SK & .769 (.436) & .643 & $.726(.446)$ & .603 & $.891(.702)$ & .883 \\
\hline & $\mathrm{AL}$ & $.713(.420)$ & .565 & $.299(.225)$ & .109 & 1.946 (1.143) & .261 \\
\hline & $\mathrm{BC}$ & $.542(.336)$ & .324 & $.431(.308)$ & .239 & $.319(.276)$ & .187 \\
\hline \multirow[t]{3}{*}{ Dependence $^{d}$} & Low & $1.637(.719)$ & .262 & $3.044(1.603)$ & .035 & $2.065(1.213)$ & .217 \\
\hline & Middle & $2.017(.953)$ & .138 & 3.625 (2.097) & .026 & $6.171(3.685)$ & .002 \\
\hline & High & 7.913 (3.511) & .000 & $6.633(4.005)$ & .002 & 9.500 (5.707) & .000 \\
\hline \multicolumn{2}{|l|}{ Disability } & 1.181 (.373) & .599 & $1.943(.734)$ & .079 & $1.393(.562)$ & .411 \\
\hline \multicolumn{2}{|c|}{ Over 3 chronic conditions } & $1.122(.416)$ & .756 & $.810(.371)$ & .645 & $.660(.279)$ & .325 \\
\hline \multicolumn{2}{|l|}{ Diabetes } & $1.246(.457)$ & .549 & $1.142(.497)$ & .761 & $.757(.338)$ & .532 \\
\hline \multicolumn{2}{|l|}{ Heart disease } & $.842(.297)$ & .625 & $2.799(1.106)$ & .009 & $1.232(.467)$ & .582 \\
\hline \multicolumn{2}{|l|}{ Stroke } & $.432(.269)$ & .178 & $2.202(1.134)$ & .125 & $1.896(1.027)$ & .238 \\
\hline \multicolumn{2}{|l|}{ Arthritis } & $.954(.319)$ & .889 & $1.137(.437)$ & .739 & $1.407(.553)$ & .385 \\
\hline \multicolumn{2}{|l|}{ Emphysema } & $1.110(.596)$ & .847 & $1.262(.789)$ & .709 & $.608(.399)$ & .448 \\
\hline Incontinence & & $.791(.321)$ & .563 & $1.168(.482)$ & .706 & $1.155(.464)$ & .721 \\
\hline
\end{tabular}

${ }^{a}$ Reference category: middle-income adequacy

${ }^{\mathrm{b}}$ Secondary education completed or higher

' Reference category: Ontario

${ }^{\mathrm{d}}$ Reference category: No dependency 
Table 9 First stage Logit equations -HMPS receipt (waves 3 to 6)

\begin{tabular}{|c|c|c|c|c|c|c|c|c|c|}
\hline \multirow{3}{*}{\multicolumn{2}{|c|}{ Dependent Variable $\rightarrow$}} & \multicolumn{4}{|l|}{ HMPS } & \multicolumn{4}{|l|}{ HMPS } \\
\hline & & \multicolumn{2}{|l|}{ Wave 3} & \multicolumn{2}{|l|}{ Wave 4} & \multicolumn{2}{|l|}{ Wave 5} & \multicolumn{2}{|l|}{ Wave 6} \\
\hline & & OR (SE) & $P$ & OR (SE) & $p$ & OR (SE) & $p$ & OR (SE) & $P$ \\
\hline \multicolumn{2}{|l|}{ HMPS $_{\mathrm{t}-2}$} & $4.704(1.319)$ & .000 & $8.883(2.812)$ & .000 & $6.138(2.018)$ & .000 & $4.580(1.648)$ & .000 \\
\hline \multicolumn{2}{|l|}{ Alzheimer } & $3.057(2.366)$ & .149 & 1 (omitted) & & 1 (omitted) & & $.977(1.228)$ & .985 \\
\hline \multirow[t]{2}{*}{ Social support } & Low & $.573(.214)$ & .136 & $1.151(.550)$ & .768 & $1.552(.746)$ & .360 & $2.684(1.345)$ & .049 \\
\hline & High & $.438(109)$ & .001 & $1.535(.509)$ & .196 & $.1 .319(447)$ & .414 & $1.202(.457)$ & .629 \\
\hline \multirow[t]{2}{*}{ Income ${ }^{a}$} & Low & $.816(.194)$ & .392 & $1.070(.274)$ & .792 & $1.827(.568)$ & .052 & $1.696(.534)$ & .094 \\
\hline & High & $.493(.148)$ & .018 & $.529(.163)$ & .039 & $.661(.229)$ & .232 & $.533(.197)$ & .089 \\
\hline \multicolumn{2}{|l|}{ Education $^{\mathrm{b}}$} & $1.382(.294)$ & .128 & $1.061(.249)$ & .799 & $1.326(.367)$ & .308 & $1.176(.314)$ & .543 \\
\hline \multicolumn{2}{|l|}{ Age } & $1.040(.017)$ & .017 & $1.051(.020)$ & .010 & $1.074(.023)$ & .001 & $1.062(.024)$ & .007 \\
\hline \multicolumn{2}{|l|}{ Sex (male) } & 1.325 (.393) & .343 & $1.333(.420)$ & .362 & $2.359(.832)$ & .015 & $2.749(.991)$ & .005 \\
\hline \multicolumn{2}{|l|}{ Partner } & $.857(.270)$ & .624 & $.658(.227)$ & .225 & $.939(.384)$ & .879 & $.921(.405)$ & .852 \\
\hline \multicolumn{2}{|l|}{ Other_adult } & $.336(.169)$ & .030 & $.582(.256)$ & .219 & $.457(.305)$ & .241 & $1.525(.737)$ & .382 \\
\hline \multicolumn{2}{|l|}{ Sex ${ }^{*}$ artner } & $.511(.249)$ & .169 & .279 (.159) & .025 & $.310(.193)$ & .060 & .286 (.186) & .054 \\
\hline \multicolumn{2}{|l|}{ Minority } & $.601(.231)$ & .186 & $.502(.227)$ & .128 & $1.381(.593)$ & .452 & $1.701(.713)$ & .205 \\
\hline \multicolumn{2}{|l|}{ Immigrant } & $.873(.245)$ & .629 & $.528(.185)$ & .068 & $.363(.154)$ & .017 & $.798(.316)$ & .570 \\
\hline \multicolumn{2}{|l|}{ Urban } & $.762(.201)$ & .301 & $.660(.193)$ & .156 & $.802(.276)$ & .521 & $1.352(.531)$ & .442 \\
\hline \multirow[t]{9}{*}{ Province ${ }^{c}$} & $N F$ & $.114(.093)$ & .007 & $.071(.062)$ & .003 & $.629(.471)$ & .536 & $.677(.447)$ & .554 \\
\hline & PEl & .706 (.294) & .403 & $.493(.220)$ & .113 & $.552(.344)$ & .340 & $1.247(.663)$ & .678 \\
\hline & NS & $1.120(.440)$ & .773 & $.716(.306)$ & .435 & $.826(.428)$ & .712 & $.615(.347)$ & .389 \\
\hline & NB & 1.027 (.395) & .944 & $.495(.243)$ & .152 & $1.074(.555)$ & .890 & 1.471 (.739) & .442 \\
\hline & $Q C$ & $.417(.169)$ & .031 & $.411(.157)$ & .020 & $.599(.257)$ & .232 & $.613(.275)$ & .275 \\
\hline & MA & $.494(.196)$ & .031 & $.949(.446)$ & .911 & $.646(.402)$ & .483 & $.467(.291)$ & .222 \\
\hline & SK & 1.477 (.515) & .263 & $.549(.243)$ & .176 & $1.655(.761)$ & .273 & $.405(.254)$ & .150 \\
\hline & $A L$ & $.620(.273)$ & .278 & $.897(.422)$ & .818 & $1.574(.773)$ & .356 & $.626(.335)$ & .381 \\
\hline & $B C$ & $.815(.301)$ & .580 & $1.122(.427)$ & .761 & $1.516(.683)$ & .355 & .635 (.292) & .324 \\
\hline \multirow[t]{3}{*}{ Dependence $^{d}$} & Low & $4.577(1.536)$ & .000 & $2.747(.868)$ & .001 & $5.453(2.549)$ & .000 & $3.937(.1 .806)$ & .003 \\
\hline & Middle & $12.30(4.268)$ & .000 & $6.923(2.403)$ & .000 & $25.32(11.84)$ & .000 & $10.04(4.647)$ & .000 \\
\hline & High & $45.35(16.36)$ & .000 & $15.66(5.619)$ & .000 & $31.73(15.67)$ & .000 & $24.09(11.55)$ & .000 \\
\hline \multicolumn{2}{|l|}{ Disability } & $1.077(.242)$ & .740 & $1.660(.423)$ & .047 & $1.136(.314)$ & .646 & $1.350(.379)$ & .286 \\
\hline \multicolumn{2}{|c|}{ Over 3 chronic conditions } & $1.242(.303)$ & .374 & $1.353(.384)$ & .287 & $.680(.216)$ & .226 & $1.141(.373)$ & .687 \\
\hline \multicolumn{2}{|l|}{ Diabetes } & $1.593(.454)$ & .102 & $1.289(.383)$ & .394 & $.819(.281)$ & .560 & $1.245(.402)$ & .498 \\
\hline Heart disease & & $1.273(.301)$ & .307 & $.942(.254)$ & .825 & $1.340(.377)$ & .299 & $1.205(.370)$ & .544 \\
\hline Stroke & & $1.305(.453)$ & .443 & $.877(.349)$ & .742 & $1.473(.657)$ & .386 & $.965(.489)$ & .944 \\
\hline Arthritis & & $.990(.221)$ & .963 & $.756(.185)$ & .252 & $1.094(.316)$ & .755 & $.931(.281)$ & .811 \\
\hline Emphysema & & $.640(.241)$ & .236 & $.828(.358)$ & .663 & $1.666(.743)$ & .253 & $1.678(.728)$ & .233 \\
\hline Incontinence & & $.940(.307)$ & .849 & $.959(.346)$ & .907 & $.900(.330)$ & .774 & $.756(.275)$ & .442 \\
\hline
\end{tabular}

${ }^{a}$ Reference category: middle-income adequacy

${ }^{b}$ Secondary education completed or higher

c Reference category: Ontario

${ }^{\mathrm{d}}$ Reference category: No dependency 
Table 10 First stage Logit equations -HMPS receipt (waves 7 to 9)

\begin{tabular}{|c|c|c|c|c|c|c|c|}
\hline \multicolumn{2}{|c|}{ Dependent Variable $\rightarrow$} & \multicolumn{6}{|l|}{ HMPS } \\
\hline & & \multicolumn{2}{|l|}{ Wave 7} & \multicolumn{2}{|l|}{ Wave 8} & \multicolumn{2}{|l|}{ Wave 9} \\
\hline & & OR (SE) & $P$ & $\mathrm{OR}(\mathrm{SE})$ & $p$ & OR (SE) & $p$ \\
\hline \multicolumn{2}{|l|}{ HMPS $_{\mathrm{t}-2}$} & $15.75(7.871)$ & .000 & $6.667(4.068)$ & .002 & $10.51(5.612)$ & .000 \\
\hline \multicolumn{2}{|l|}{ Alzheimer } & $4.780(8.122)$ & .357 & 1 (omitted) & & $1.087(1.193)$ & .940 \\
\hline \multirow[t]{2}{*}{ Social support } & Low & $2.390(1.749)$ & .234 & $.491(.396)$ & .377 & $.298(.252)$ & .152 \\
\hline & High & $1.993(1.003)$ & .170 & $1.599(.718)$ & .296 & $1.067(.459)$ & 879 \\
\hline \multirow[t]{2}{*}{ Income ${ }^{a}$} & Low & $1.084(.503)$ & .862 & $1.638(.779)$ & .299 & $1.415(.714)$ & .492 \\
\hline & High & $.784(.345)$ & .580 & $1.204(.448)$ & .617 & $.728(.291)$ & .428 \\
\hline \multicolumn{2}{|l|}{ Education ${ }^{\mathrm{b}}$} & $.467(.170)$ & .037 & $.688(.225)$ & .253 & $1.176(.426)$ & .654 \\
\hline \multicolumn{2}{|l|}{ Age } & $1.088(.033)$ & .006 & $1.096(.029)$ & .001 & $1.138(.035)$ & .000 \\
\hline \multicolumn{2}{|l|}{ Sex (male) } & $2.009(1.021)$ & .170 & $1.897(.960)$ & .206 & $5.662(2.723)$ & .000 \\
\hline \multicolumn{2}{|l|}{ Partner } & $.716(.418)$ & .568 & $.815(.376)$ & .657 & $.977(.525)$ & .966 \\
\hline \multicolumn{2}{|l|}{ Other_adult } & $.894(.653)$ & .878 & $.281(.215)$ & .097 & $.140(.158)$ & .081 \\
\hline \multicolumn{2}{|l|}{ Sex*partner } & $.602(.477)$ & .522 & $.308(.226)$ & .108 & $.087(.070)$ & .002 \\
\hline \multicolumn{2}{|l|}{ Minority } & $1.088(.588)$ & .877 & $.760(.438)$ & .634 & $.529(.355)$ & .343 \\
\hline \multicolumn{2}{|l|}{ Immigrant } & $.955(.485)$ & .927 & $.976(.452)$ & .958 & $.411(.277)$ & .188 \\
\hline \multicolumn{2}{|l|}{ Urban } & $1.175(.626)$ & .763 & $.648(.283)$ & .321 & $.640(.314)$ & .363 \\
\hline \multirow[t]{9}{*}{ Province $^{c}$} & NF & $.600(.523)$ & .558 & $.325(.282)$ & .194 & $1.522(1.360)$ & .639 \\
\hline & PEl & $.702(.444)$ & .576 & $1.118(.725)$ & .864 & $2.134(1.646)$ & .326 \\
\hline & NS & $.521(.370)$ & .359 & $.649(.410)$ & .494 & $2.283(1.580)$ & .233 \\
\hline & NB & $.633(.385)$ & .452 & $.792(.531)$ & .727 & $4.714(3.101)$ & .018 \\
\hline & QC & $.462(.276)$ & .196 & $1.301(.626)$ & .584 & $1.902(1.099)$ & .266 \\
\hline & MA & $.314(.290)$ & .210 & $.487(.322)$ & .276 & $7.091(4.689)$ & .003 \\
\hline & SK & $.211(.171)$ & .055 & $.557(.379)$ & .390 & $.808(.720)$ & .811 \\
\hline & $\mathrm{AL}$ & .199 (.173) & .063 & $.563(.399)$ & .418 & 1.976 (1.590) & .397 \\
\hline & $B C$ & $.541(.354)$ & .348 & .795 (.528) & .730 & $1.753(1.216)$ & .419 \\
\hline \multirow[t]{3}{*}{ Dependence $^{d}$} & Low & $2.346(1.268)$ & .114 & $5.815(2.814)$ & .000 & $1.453(.755)$ & .473 \\
\hline & Middle & $6.716(3.379)$ & .000 & $13.71(7.038)$ & .000 & 7.019 (3.788) & .000 \\
\hline & High & $16.56(9.262)$ & .000 & $54.91(34.15)$ & .000 & $9.383(5.315)$ & .000 \\
\hline \multicolumn{2}{|l|}{ Disability } & $1.579(.581)$ & .214 & $1.145(.382)$ & .685 & $1.107(.425)$ & .791 \\
\hline \multicolumn{2}{|c|}{ Over 3 chronic conditions } & $.714(.302)$ & .426 & $.613(.245)$ & .221 & $.554(.244)$ & .180 \\
\hline \multicolumn{2}{|l|}{ Diabetes } & $.880(.421)$ & .790 & $1.294(.539)$ & .536 & $3.492(1.549)$ & .005 \\
\hline \multicolumn{2}{|l|}{ Heart disease } & $.609(.264)$ & .252 & $.915(.362)$ & .823 & $1.538(.612)$ & .279 \\
\hline \multicolumn{2}{|l|}{ Stroke } & $.381(.352)$ & .297 & $.192(.172)$ & .066 & $1.041(.704)$ & .953 \\
\hline \multicolumn{2}{|l|}{ Arthritis } & $2.272(.962)$ & .053 & $1.602(.571)$ & .187 & $2.136(.853)$ & .057 \\
\hline Emphysema & & $.437(.357)$ & .311 & $1.508(.845)$ & .463 & $1.020(.712)$ & .978 \\
\hline Incontinence & & $.945(.456)$ & .907 & $.380(.183)$ & .044 & $2.254(.960)$ & .056 \\
\hline
\end{tabular}

${ }^{a}$ Reference category: middle-income adequacy

${ }^{b}$ Secondary education completed or higher

c Reference category: Ontario

${ }^{\mathrm{d}}$ Reference category: No dependency 


\section{Abbreviations}

ADLs/IADLs: activities of daily living/instrumental activities of daily living; AHEAD: asset and health dynamics among the oldest-old; AIC: Akaike's information criterion; AL: Alberta; BC: British Columbia; GEE: generalized estimating equations; $\mathrm{HC}$ : home care; HHC: home health care; HMPS: homemaking/personal support; IV: instrumental variable: MA: Manitoba; NB: New Brunswick; NF: Newfoundland \& Labrador; NPHS: national population health survey; NS: Nova Scotia; ON: Ontario; PEl: Prince Edward Island; QC: Québec; SHARE: survey of health, ageing and retirement in Europe; SK: Saskatchewan.

\section{Competing interests}

The authors declare that have no competing interests.

\section{Authors' contributions}

GM designed the analysis, conducted the data analysis and wrote the manuscript. WPW and AL made substantial contributions to the design, data analysis and interpretation, and were involved in drafting the manuscript and revising it critically. All authors gave final approval to this manuscript.

\section{Acknowledgements}

This work was supported by funding from the Health System Performance Research Network (MOHLTC Grant No. 06034) and by a grant from the Canadian Institute for Health Research (CIHR grant 84310). We would like to acknowledge Statistics Canada for granting data access and helpful comments and suggestions provided by Dr. Whitney Berta and Dr. Courtney Van Houtven. All errors are the sole responsibility of the authors.

\section{Received: 23 July 2015 Accepted: 13 October 2015}

\section{Published online: 25 February 2016}

\section{References}

1. World Health Organization. Home-based long-term care. Rep. No. 898. Geneva: World Health Organization; 2000

2. Ovseiko P. Long-term care for older people. Oxford: Oxford Institute of Aging; 2007.

3. Payne G, Laporte A, Deber R, Coyte PC. Counting backward to health care's future: using time-to-death modeling to identify changes in end-of-life morbidity and the impact of aging on health care expenditures. Milbank Q. 2007:85:213-57.

4. McGrail K, Green B, Barer ML, Evans RG, Hertzman C, Normand C. Age, costs of acute and long-term care and proximity to death: evidence for 1987-88 and 1994-95 in British Columbia. Age Ageing. 2000;29:249-53.

5. Wilkins K, Park E. Home care in Canada. Rep. No. 10. Ottawa: Statistics Canada; 1998

6. Kirby MJ. The health of Canadians: the federal role. Volume six: recommendations for reform. Ottawa; 2002. http://www.cimca.ca/i/m/TheComplete-Kirby-Report.pdf.

7. Colombo F. Help wanted? Providing and paying for long-term care. Paris: OECD Publishing; 2011

8. Williams AP, Challis D, Deber R, Watkins J, Kuluski K, Lum JM, et al. Balancing institutional and community-based care: why some older persons can age successfully at home while others require residential long-term care. Healthc Q. 2009:12:95-105.

9. Kemper P. The use of formal and informal home care by the disabled elderly. Health Serv Res. 1992;27:421-51.

10. Ettner SL. The effect of the medicaid home care benefit on long-term care choice of the elderly. Econ Inq. 1994;32(10):103-27.

11. Hoerger TJ, Picone GA, Sloan FA. Public subsidies, private provision of care and living arrangements of the elderly. Rev Econ Stat. 1996;78(3):428-40.

12. Pezzin LE, Kemper P, Reschovsky J. Does publicly provided home care substitute for family care? Experimental evidence with endogenous living arrangements. J Hum Resour. 1996;31(3):650-76.

13. Stoddart H, Whitley E, Harvey I, Sharp D. What determines the use of home care services by elderly people? Health Soc Care Community. 2002;10:348-60

14. van Campen C, Woittiez IB. Client demands and the allocation of home care in the Netherlands. A multinomial logit model of client types, care needs and referrals. Health Policy. 2003;64:229-41.

15. Van Houtven $\mathrm{CH}$, Norton EC. Informal care and health care use of older adults. J Health Econ. 2004;23:1159-80.
16. Van Houtven $\mathrm{CH}$, Norton EC. Informal care and medicare expenditures: testing for heterogeneous treatment effects. J Health Econ. 2008;27:134-56.

17. Meinow B, Kareholt I, Lagergren M. According to need? Predicting the amount of municipal home help allocated to elderly recipients in an urban area of Sweden. Health Soc Care Community. 2005;13:366-77.

18. van Campen C, van Gameren E. Eligibility for long-term care in The Netherlands: development of a decision support system. Health Soc Care Community. 2005;13:287-96

19. Guerriere DN, Wong AY, Croxford R, Leong WW, McKeever P, Coyte PC. Costs and determinants of privately financed home-based health care in Ontario, Canada. Health Soc Care Community. 2008;16:126-36.

20. Blomgren J, Martikainen P, Martelin T, Koskinen S. Determinants of homebased formal help in community-dwelling older people in Finland. Eur J Ageing. 2008:5:335-47.

21. Hammar T, Rissanen P, Perala ML. Home-care clients' need for help, and use and cost of services. Eur J Ageing. 2008;5:147-60.

22. Bonsang $E$. Does informal care from children to their elderly parents substitute for formal care in Europe? J Health Econ. 2009;28:143-54.

23. Coyte P, Guerriere D, McKeever P. Determinants and outcomes of privately and publicly financed home-based nursing. Ottawa: Canadian HealthServices Research Foundation; 2010.

24. Larsson K, Thorslund M, Kareholt I. Are public care and services for older people targeted according to need? Applying the behavioural model on longitudinal data of a Swedish urban older population. Eur J Ageing. 2006;3:22-33.

25. Bolin K, Lindgren B, Lundborg P. Informal and formal care among singleliving elderly in Europe. Health Econ. 2008;17:393-409.

26. Laporte A, Croxford R, Coyte PC. Can a publicly funded home care system successfully allocate service based on perceived need rather than socioeconomic status? A Canadian experience. Health Soc Care Community. 2007:15:108-19.

27. Wilson D, Truman CD, Huang J, Sheps S, Thomas R, Noseworthy T. The possibilities and the realities of home care. Can J Public Health. 2005;96: 385-9.

28. Coyte PC, Guerriere D, McKeever P. Determinants and outcomes of privately and publicly financed home-based nursing. Ottawa: Canadian Health Services Research Foundation; 2006.

29. Coyte PC, McKeever P. Home care in Canada: passing the buck. Can J Nurs Res. 2001:33:11-25.

30. Canadian Institute for Health Information. Public-sector expenditures and utilization of home care in Canada: exploring the data. Ottawa; 2007.

31. Baranek PM, Deber RB, Williams AP. Introduction and overview. In almost home: reforming home and community care in ontario. Toronto: University of Toronto Press; 2004

32. McGrail KM, Broemeling A, McGregor MJ, Salomons K, Ronald LA, McKendry R. Home health services in British Columbia: a portrait of users and trends over time. Vancouver: The University of British Columbia; 2008.

33. Canadian Home Care Association. Portraits of home care. 2008. http://www. cdnhomecare.ca. Accessed 23 Dec 2011.

34. Mery G, Wodchis WP, Laporte A. The determinants of the propensity to receive publicly funded home care services for the elderly in Canada: a panel two-stage residual inclusion approach. Working paper series. No. 2014-14. Toronto: Canadian Centre for Health Economics; 2014.

35. Statistics Canada. National population health survey, household component, cycles 1 to 8 (1994/1995 to 2008/2009). Ottawa: Longitudinal Documentation; 2010. http://www23.statcan.gc.ca/imdb-bmdi/document/ 3225_D5_T1_V5-eng.pdf.

36. Rivers D, Vuong QH. Limited information estimators and exogeneity tests for simultaneous probit models. J Econometrics. 1988;39:347-66.

37. Terza JV, Basu A, Rathouz PJ. Two-stage residual inclusion estimation: addressing endogeneity in health econometric modeling. J Health Econ. 2008;27:531-43.

38. Ontario Ministry of Health and Long Term Care. Aging at home strategy. Newsroom. 2010. http://news.ontario.ca/mohltc/en/2010/08/aging-at-homestrategy.html. Accessed 13 Apr 2015.

39. Ontario Ministry of Health and Long Term Care: Excelent Care for All. http://www.health.gov.on.ca/en/pro/programs/ecfa/action/community/ com_homefirst.aspx. (2014). Accessed 13 Apr 2015.

40. Schoenmakers B, Buntinx F, DeLepeleire J. Supporting the dementia family caregiver: the effect of home care intervention on general well-being. Aging Ment Health. 2010;14(1):44-56.

41. Hausman JA. Specification tests in econometrics. Econometrica. 1978:46:1251-71. http//econweb.tamu.edu/keli/Hausman\%201978.pdf. 
42. McAuley WJ, Spector W, Van Nostrand J. Formal home care utilization patterns by rural-urban community residence. J Gerontol B Psychol Sci Soc Sci. 2009;64:258-68.

43. Kempen Gl, Suurmeijer TP. Factors influencing professional home care utilization among the elderly. Soc Sci Med. 1991;32:77-81.

44. Coughlin TA, McBride TD, Perozek M, Liu K. Home care for the disabled elderly: predictors and expected costs. Health Serv Res. 1992;27:453-79.

45. Forbes DA, Jansen SL, Markle-Reid M, Hawranik P, Morgan D, Henderson S, et al. Gender differences in use and availability of home and communitybased services for people with dementia. Can J Nurs Res. 2008;40:39-59.

46. Stabile M, Laporte A, Coyte PC. Household responses to public home care programs. J Health Econ. 2006;25:674-701.

47. Canadian Minister of Justice. Employment equity act. 10-3-2010. Ottawa; 1995.

\section{Submit your manuscript to a SpringerOpen ${ }^{\odot}$ journal and benefit from:}

- Convenient online submission

- Rigorous peer review

- Immediate publication on acceptance

- Open access: articles freely available online

- High visibility within the field

- Retaining the copyright to your article

Submit your next manuscript at $>$ springeropen.com 